ISSN 1980-5098

\title{
MAPEAMENTO DAS ÁREAS DE PRESERVAÇÃO PERMANENTE DO ESTADO DO ESPÍRITO SANTO, BRASIL
}

\section{MAPPING OF PERMANENT PRESERVATION AREAS OF THE STATE ESPIRITO SANTO, BRAZIL}

\author{
Fernando Coelho Eugenio $^{1}$ Alexandre Rosa dos Santos ${ }^{2}$ Nilton Cesar Fiedler ${ }^{3}$ \\ Guido Assunção Ribeiro ${ }^{\dagger 6}$ Aderbal Gomes da Silva ${ }^{3}$ Vicente Paulo Soares ${ }^{4}$ José Marinaldo Gleriani ${ }^{5}$
}

\section{RESUMO}

O estudo foi realizado em todo o estado do Espírito Santo, com o objetivo de delimitar as Áreas de Preservação Permanentes (APPs) na ótica da Lei 12.651/2012 (Código Florestal) e ressaltar a importância de identificar as áreas de forma automática. Cada APP possui uma metodologia própria para o seu mapeamento, entretanto, todas foram mapeadas com o auxílio de geotecnologia. O estado possui $22,43 \%$ de sua área de APPs, distribuídas ao longo da faixa marginal dos cursos d'água (10,42\%); no entorno de lagos e lagoas naturais $(0,67 \%)$; no entorno dos reservatórios d'água artificiais $(0,02 \%)$; no entorno das nascentes $(0,89 \%)$; em encostas com declividades superiores a $45^{\circ}(0,24 \%)$; em restingas $(1,92 \%)$; em manguezais $(0,19 \%)$; em topo de morros $(8,98 \%)$; e em altitudes superiores a 1.800 metros $(0,19 \%)$ da área total do estado. O presente estudo serve como subsídio técnico para avaliação e quantificação da APPs em um Estado, visto que é o primeiro em nível estadual no Brasil sobre o tema.

Palavras-chave: proteção florestal; geoprocessamento; política florestal.

\begin{abstract}
The study was conducted across the state of Espirito Santo, with the objective of limiting the Permanent Preservation Areas (PPAs) by optical law 12.651/2012 (forest code) and highlight the importance of identifying those areas automatically. Each PPA has its own methodology for their mapping, however, all were mapped with the aid of geotechnology. The state has $22.43 \%$ of its PPA area distributed along the marginal strip watercourses $(10.42 \%)$; in the surroundings of lakes and natural ponds $(0.67 \%)$; around the artificial water reservoirs $(0.02 \%)$, in the vicinity of springs $(0.89 \%)$ in the hillsides with slopes greater than $45^{\circ}(0.24 \%)$; in restingas $(1.92 \%)$; in mangroves $(0.19 \%)$; on top of hills $(8.98 \%)$; and in higher than 1800 meters $(0.19 \%)$ of the total area of the state altitudes. This study serves as a technical subsidy for evaluation and quantification of PPAs in a State, since it is the first one in a state level in Brazil on the issue.
\end{abstract}

Keywords: forest protection; GIS; forest policy.

1 Engenheiro Florestal, Doutorando do Programa de Pós-Graduação em Ciências Florestais, Universidade Federal do Espírito Santo / Universitat de Barcelona, Av. Governador Lindemberg, 316, CEP 29550-000, Jerônimo Monteiro (ES), Brasil. coelho.fernando@yahoo.com.br

2 Engenheiro Agrônomo, Dr., Professor do Departamento de Engenharia Rural, Universidade Federal do Espírito Santo, Alto Universitário, s/n, Guararema, Caixa Postal 16, CEP 29500-000, Alegre (ES), Brasil. mundogeomatica@yahoo.com.br

3 Engenheiro Florestal, Dr., Professor do Departamento de Ciências Florestais e da Madeira, Universidade Federal do Espírito Santo, Av. Governador Lindemberg, 316, CEP 29550-000, Jerônimo Monteiro (ES), Brasil. nilton. fiedler@ufes.br / aderbalsilva@yahoo.com

4 Engenheiro Florestal, Dr., Professor do Departamento de Engenharia Florestal, Universidade Federal de Viçosa, Avenida Peter Henry Rolfs, s/n, Campus Universitário, CEP 36570-000, Viçosa (MG), Brasil. soares@ufv.br

5 Engenheiro Agrônomo, Dr., Professor do Departamento de Engenharia Florestal, Universidade Federal de Viçosa, Avenida Peter Henry Rolfs, s/n, Campus Universitário, CEP 36570-000, Viçosa (MG), Brasil. gleriani@gmail.com

6 Engenheiro Florestal, Dr., Professor do Departamento de Engenharia Florestal, Universidade Federal de Viçosa, Av. P.H Rolfs, s/n, Campus Universitário, CEP 36570-000, Vicosa (MG), Brasil. `In memorian

Recebido para publicação em 12/09/2014 e aceito em 10/03/2016

Ci. Fl., v. 27, n. 3, jul.-set., 2017 


\section{INTRODUÇÃO}

De acordo com o Código Florestal Brasileiro (BRASIL, 2012), as APPs são fundamentais para a manutenção da vegetação de determinadas áreas, com o objetivo de manter inalterado o uso da terra, que deve estar coberto pela vegetação original.

Segundo Hott, Guimarães e Miranda (2004), em um país de dimensões continentais como o Brasil, torna-se indispensável a representação e caracterização das APPs em mapas, pois é de suma importância para o planejamento territorial, na fiscalização e nas ações de campo de âmbito local, regional ou nacional. Eugenio et al. (2013) ressaltaram que, apesar de o Brasil possuir uma legislação ambiental considerada por muitos como uma das melhores do mundo, a mesma é deficiente em sua implementação devido, principalmente, à grande extensão territorial do país, o que a torna lenta e pouco eficaz na prática.

As metodologias que utilizam a geotecnologia como ferramenta principal vêm se destacando, sendo a alternativa mais viável para se reduzir significativamente o tempo gasto com o mapeamento das áreas a serem protegidas e, por consequência, agilizar o período hábil de fiscalização do cumprimento das leis pertinentes à legislação.

O objetivo deste trabalho foi identificar e delimitar de forma automática as APPs, na ótica da legislação ambiental vigente, para todo o estado do Espírito Santo e demonstrar como a geotecnologia pode auxiliar neste processo.

\section{MATERIAL E MÉTODO}

A área de estudo é representada pelo estado do Espírito Santo, localizado na região sudeste do Brasil, o qual apresenta divisas com os estados do Rio de Janeiro ao sul, Minas Gerais ao leste e Bahia ao norte, possuindo uma área territorial de $46.052,64 \mathrm{~km}^{2}$.

A base de dados correspondente aos cursos d'água (rede hidrográfica perene e intermitentes, excluído os efêmeros), lagos e lagoas, reservatórios d'água, mancha urbana e uso e ocupação da terra do ano de 2010, foram disponibilizadas pelo Sistema Integrado de Bases Geoespaciais do Estado do Espírito Santo (GEOBASES).

\section{Desenvolvimento do Modelo Digital de Elevação (MDE)}

Os dados utilizados para geração do Modelo Digital de Elevação (MDE) foram as curvas de nível na escala de 1:35.000, cedidas pelo Instituto Estadual do Meio Ambiente (IEMA), adotando a exatidão cartográfica de $0,143 \mathrm{~mm}$. Assim, para determinar a menor dimensão no terreno representada no mapa, ou seja, a resolução espacial das células do MDE, multiplicou-se a exatidão cartográfica pelo fator de escala, que correspondeu a 5 metros. Entretanto, para fins desse estudo, adotou-se em todo o trabalho, devido às limitações tecnológicas, o dimensionamento das células de 30 metros.

Determinada a dimensão da célula de saída e de posse dos referidos dados, a geração do MDE para o estado foi realizada utilizando o algoritmo de interpolação TOPO TO RASTER, disponível no aplicativo computacional ArcGIS 10.2.1. Em seguida, foram realizadas operações com a finalidade de identificar e eliminar a ocorrência de imperfeições (depressões espúrias) no MDE, para criação de uma calha ao longo da rede hidrográfica, objetivando garantir a convergência do escoamento superficial até a foz da hidrografia.

\section{Delimitação das APPs}

De posse do MDE, iniciou-se o mapeamento automático das APPs da área de estudo, considerando: a faixa marginal dos cursos d'água; entorno dos lagos e lagoas; o entorno dos reservatórios d'água artificiais; o entorno das nascentes; as encostas com declividades acima de 45 graus; as restingas; os manguezais; os topos de morros e montanhas (terço superior); e as áreas com altitudes superiores a 1.800 metros, baseando- 
se nos critérios estabelecidos pela Lei no 12.651 (BRASIL, 2012), a qual dispõe sobre parâmetros, definições e limites das APPs.

\section{Delimitação das APPs ao longo da faixa marginal dos cursos d'água}

A partir da rede hidrográfica do estado, avaliou-se a largura média dos rios, sobrepondo-os às aerofotos ortorretificadas do ano de 2007, na escala 1:35.000, cedidas pelo IEMA(1 m de resolução espacial), por medição em tela, medindo perpendicularmente ao fluxo de água, possibilitando assim verificar a largura entre as bordas dos rios, classificando-os conforme previsto em lei, sendo os intervalos representados pela Tabela 1.

TABELA 1: Classificação da largura dos cursos d'água com sua respectiva faixa de APP.

TABLE 1: Classification width of waterways with their respective strip of PPA.

\begin{tabular}{ccc}
\hline Classes & Largura $(\mathrm{m})$ & Faixa de APP $(\mathrm{m})$ \\
\hline 1 & $<10$ & 30 \\
2 & $10+50$ & 50 \\
3 & $50 \vdash 200$ & 100 \\
4 & $200+600$ & 200 \\
5 & $\geq 600$ & 500 \\
\hline
\end{tabular}

A delimitação das áreas de preservação ao longo dos cursos d'água foi realizada por meio da técnica de análise de proximidade (buffer zone), dentro do aplicativo computacional ArcGIS 10.2.1. DeMers (1997) relata que uma zona de contenção legal é a largura em relação a um objeto determinado por força de lei. O mesmo autor cita como exemplo as APPs que estão próximas de córregos e rios. O rio Doce, importante rio, que em seu curso passa pelos estados de Minas Gerais e Espírito Santo, foi dividido em dois, visto que, no trecho que compreende o limite do estado do Espírito Santo até a divisa oeste do município de Linhares, sua largura média fica entre 200 e 600 metros. Já a sua largura após adentrar no município indo até sua jusante, possui valores médios acima de 600 metros.

Os limites da expressão geográfica dos rios foram digitalizados em tela sobre a aerofoto disponibilizada pelo IEMA, criando um arquivo poligonal. Entretanto, ressalta-se que, na classe 1 não foi feita a digitalização dos limites dos cursos d'água, sendo a mesma feita apenas sobre os trechos dos rios com largura acima de 30 metros, classes 2 a 5, ou seja, os rios de classes 2 a 5 tiveram seus buffers realizados a partir da borda da calha de seu leito regular, enquanto os de classe 1 tiveram seus buffers a partir da linha representativa da calha dos rios.

\section{Delimitação das APPs no entorno de lagos e lagoas naturais}

Com o arquivo poligonal representativo dos lagos e lagoas, criou-se um campo na tabela de atributos, e por meio da mapemática, funções algébricas dentro de um SIG, realizou-se o cálculo das áreas de cada polígono em hectares. Foi necessário verificar a localização dos polígonos referentes aos lagos e lagoas, para isso, utilizou-se o arquivo poligonal representativo das áreas de mancha urbana, fornecido pelo GEOBASES. De posse das manchas urbanas, efetuou-se a separação dos lagos e lagoas em áreas urbanas e rurais, classificando-os conforme previsto em lei, sendo que na zona rural lagos e lagoas com superfície entre 1 e 20 ha necessitam de uma faixa de no mínimo 50 metros de APP e superfície maior que 20 ha necessita de uma faixa de no mínimo 100 metros de APP; na zona urbana, independentemente do tamanho da superfície os lagos e lagoas necessitam ter uma faixa de no mínimo 30 metros. Caso o lago ou lagoa esteja com mais de $50 \%$ de sua área fora de uma zona urbana, o polígono foi considerado zona rural. $\mathrm{O}$ 
mesmo vale para o oposto da situação apresentada.

Ressalta-se que no parágrafo quarto do artigo 4 da Lei 12.651 (BRASIL, 2012), fica dispensada a reserva da faixa de preservação previstas no inciso II do caput, ou seja, não foi gerado APP no entorno dos lagos e lagoas com superfície inferior a 1 hectare. A delimitação das áreas de preservação no entorno dos lagos e lagoas foi realizada por meio da técnica de análise de proximidade (buffer).

\section{Delimitação das APPs no entorno dos reservatórios d'água artificiais}

O inciso III do artigo 4 da Lei 12.651 (BRASIL, 2012), dispõe que as áreas no entorno dos reservatórios artificiais, decorrentes de barramento ou represamento de cursos d'água naturais, terá sua faixa de preservação permanente definida na licença ambiental do empreendimento. Contudo, para fins desse estudo, consideraram-se as APPs dos reservatórios artificiais, sendo idênticas aos das APPs de lagos e lagoas, ou seja, foi realizado o mapeamento conforme os parâmetros dispostos no inciso II do artigo 4 da Lei 12.651 (BRASIL, 2012), o qual define as faixas de APPs de lagos e lagoas. Esta decisão foi tomada para que não houvesse uma subestimação das áreas de APPs no estado.

De posse do arquivo poligonal representativo dos reservatórios d'água, criou-se um campo na tabela de atributos, e por meio da mapemática, realizou-se o cálculo das áreas de cada polígono em hectares. Foi necessário verificar a localização dos polígonos referentes aos reservatórios d'água, e para tal, utilizouse o arquivo poligonal representativo das áreas de mancha urbana. Com as manchas urbanas, efetuou-se a separação dos reservatórios d'água presentes em áreas urbanas e rurais.

A delimitação das áreas de preservação no entorno dos reservatórios d'água foi realizada por meio da técnica de análise de proximidade (buffer).

\section{Delimitação das APPs no entorno das nascentes}

Para se iniciar a delimitação das APPs no entorno das nascentes, foi necessária a criação de um arquivo vetorial de pontos. Com o auxílio da base de dados correspondentes aos cursos d'água do estado do Espírito Santo, foi realizada a digitalização em tela do arquivo vetorial de pontos criados. Para fins desse estudo, considerou-se que a cada início de rio tem-se apenas uma nascente, ou seja, em cada início de rio, extremidade a montante, foi digitalizado um ponto referente a uma nascente.

A delimitação das áreas de preservação no entorno das nascentes foi realizada por meio da técnica de análise de proximidade (buffer), delimitando-se um raio de preservação de 50 metros no entorno de cada ponto do arquivo vetorial representativo das nascentes do estado.

\section{Delimitação das APPs em encostas com declividades superiores a $4^{\circ}$}

A partir do MDE, inicialmente, foi elaborado o mapa matricial de declividade da área de estudo utilizando a função $S L O P E$. Posteriormente, foi realizado a separação do mapa matricial em duas classes, acima de $45^{\circ}$ de inclinação e abaixo de $45^{\circ}$

\section{Delimitação das APPs em restingas e manguezais}

O inciso VI do artigo 4 da Lei 12.651 (BRASIL, 2012) considera que todas as restingas, como fixadoras de dunas ou estabilizadoras de mangues, e toda a extensão dos manguezais são áreas de preservação permanente. Para o mapeamento, utilizou-se o arquivo vetorial poligonal do uso e ocupação da terra do ano de 2010 para o estado do Espírito Santo. Com o arquivo, realizou-se a exportação dos campos pertinentes as restingas e ao manguezal, gerando dois novos arquivos denominados de APP restinga e APP manguezais, visto que a área de preservação é a própria restinga e o próprio manguezal.

\section{Delimitação das APPs em topo de morros}

Com o MDE, foi realizado o refinamento para remoção de depressões espúrias do mesmo e, 
posteriormente, foi feita a geração dos cumes de cada morro, montes, montanhas e serras. De posse dos cumes de cada morro foi realizado o mapeamento das elevações. Reclassificaram-se as elevações geradas e com o auxílio da ferramenta "calculadora de mapas" foram inseridos os parâmetros contidos na legislação vigente, resultando na determinação do terço superior. As etapas necessárias para a elaboração das APPs de topo de morro são mostradas na Figura 1.

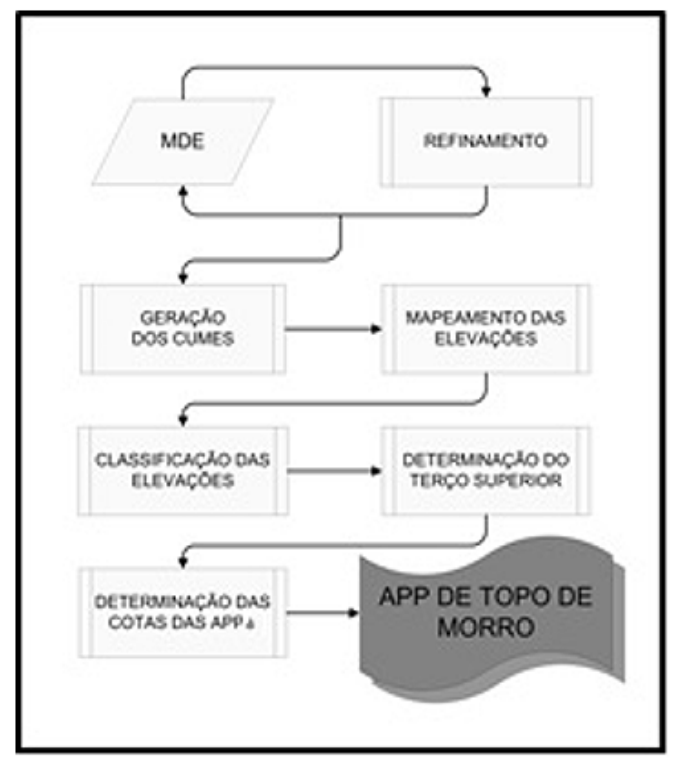

FIGURA 1: Fluxograma das etapas na determinação de APPs de topo de morro.

FIGURE 1: Flowchart of the steps in determining the PPAs hilltop.

Na Figura 2 é apresentado uma representação simplificada da APP em topo de morro.

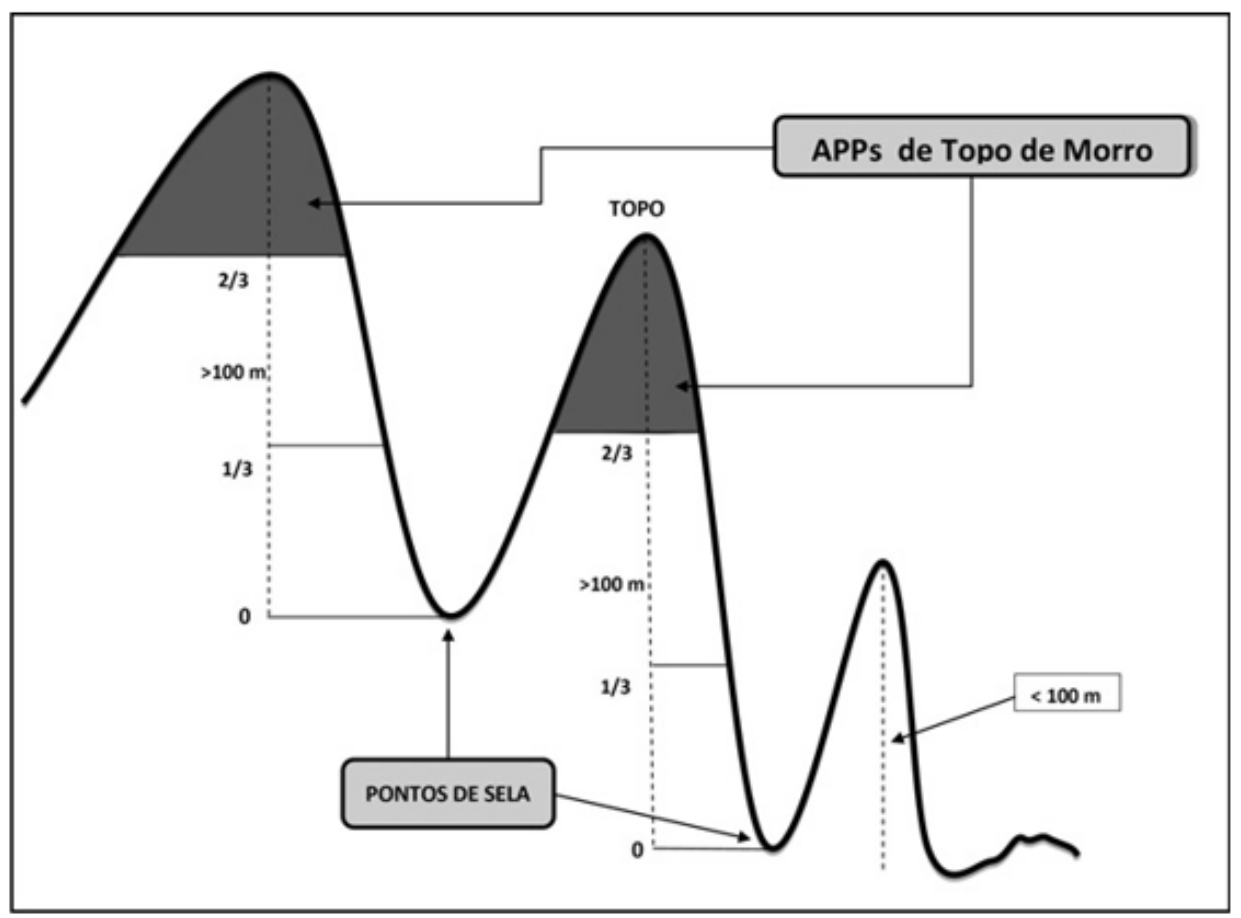

Fonte: EMBRAPA (2013) - Adaptado pelo autor

FIGURA 2: Representação da APP de topo de morro.

FIGURE 2: Representation of the APP hilltop. 


\section{Delimitação das APPs em altitudes superiores a 1.800 metros}

De posse do MDE, foi realizada uma reclassificação de modo que se obteve um novo arquivo matricial contendo duas classes: superior a 1.800 metros (valor 1) e inferior a 1.800 metros (NoData). Com o novo arquivo matricial de altitude, agora reclassificada, foi realizada uma conversão de arquivo raster para arquivo vetorial poligonal, representativo das áreas de preservação permanente superior a 1.800 metros para o estado do Espírito Santo.

\section{RESULTADOS E DISCUSSÃO}

A metodologia de delimitação automática das APPs, tendo como referência legal a Lei 12.651 (BRASIL, 2012), possibilitou identificar e quantificar as APPs. A Tabela 2 apresenta os resultados, em porcentagem, das áreas ocupadas pelas APPs no estado do Espírito Santo.

TABELA 2: Porcentagem das áreas ocupadas pelas APPs no estado do Espírito Santo.

TABLE 2: Percentage of areas occupied by the PPA in the state of Espirito Santo.

\begin{tabular}{ccccc}
\hline APPs & Denominação & Característica & Área $\left(\mathrm{km}^{2}\right)$ & $\begin{array}{c}\% \text { ocupada em } \\
\text { relação ao estado }\end{array}$ \\
\hline APP-1 & Cursos d'água & Buffers de 30, 50, 100, 200 ou 500 m & $4.798,35$ & 10,42 \\
APP-2 & Lagos e lagoas & Buffers de 30,50 ou $100 \mathrm{~m}$ & 309,82 & 0,67 \\
APP-3 & Represas artificiais & Buffers de 30, 50 ou $100 \mathrm{~m}$ & 9,90 & 0,02 \\
APP-4 & Nascentes & Raio de 50 m & 411,08 & 0,89 \\
APP-5 & Declividade & Acima de $45^{\circ}$ & 112,48 & 0,24 \\
APP-6 & Restinga & Área ocupada & 885,45 & 1,92 \\
APP-7 & Manguezal & Área ocupada & 88,49 & 0,19 \\
APP-8 & Topo de morro & Terço superior de morro & $1.817,99$ & 3,95 \\
APP-9 & Altitude & Superior a $1.800 \mathrm{~m}$ & 85,48 & 0,19 \\
\hline TOTAL & & Soma simples & $8.519,03$ & 18,50 \\
\hline TOTAL & & Soma sem sobreposições & $7.978,44$ & 17,32 \\
\hline
\end{tabular}

A Figura 3 apresenta a distribuição das APPs no estado do Espírito Santo. As APPs ao longo da faixa marginal dos cursos d'água garantem a estabilização das margens tendo assim, uma importância vital no controle da erosão do solo e da qualidade da água, evitando o carreamento direto para o ambiente aquático de sedimentos, nutrientes e produtos químicos provenientes das partes mais altas do terreno, os quais afetam a qualidade da água, diminuem a vida útil dos reservatórios, das instalações hidroelétricas e dos sistemas de irrigação (EUGENIO et al., 2010). A área ocupada pelas APPs ao longo da faixa marginal dos cursos d'água representaram $10,42 \%$ de todo o território estadual, totalizando $4.798,35 \mathrm{~km}^{2}$.

As APPs ao redor de lagos e lagoas naturais possuem papel similar ao das APPs de cursos d'água, visto que, protegem contra a erosão do solo e ajudam na melhoria da qualidade da água (TUNDISI, 2008). As APPs ao redor de lagos e lagoas naturais representam $0,67 \%$ do território estadual, o que totaliza uma 


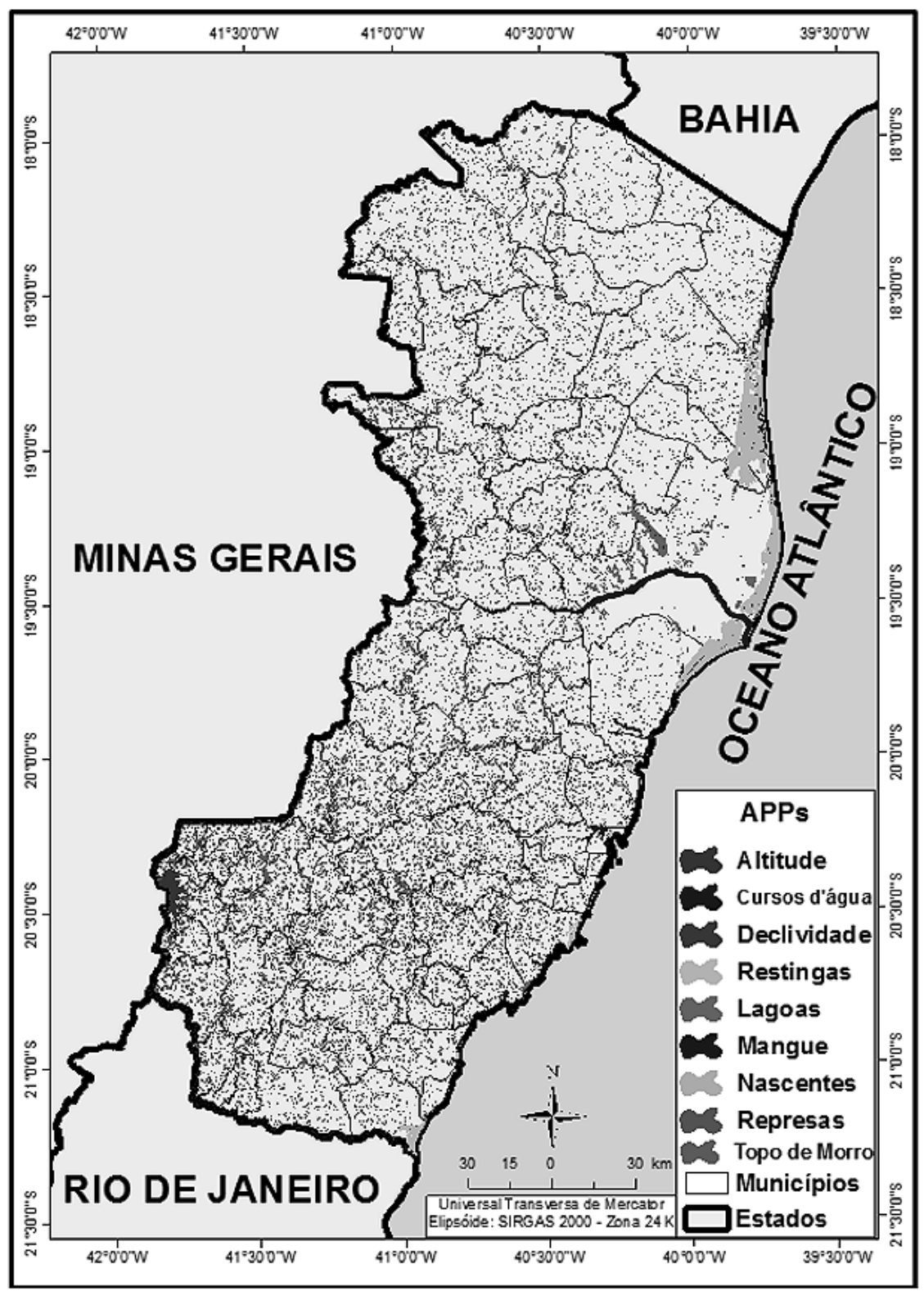

FIGURA 3: Total das APPs no estado do Espírito Santo.

FIGURE 3: Total PPA in the state of Espirito Santo

extensão de superfície de $309,82 \mathrm{~km}^{2}$.

As APPs no entorno dos reservatórios d'água artificiais representaram $0,02 \%$ do território estadual, o que totaliza uma extensão de superfície de $9,90 \mathrm{~km}^{2}$. Apesar da pequena representatividade perante a área do estado, a mesma possui papel importante e similar ao das APPs de cursos d'água e APPs de lagos e lagoas, visto que protegem contra a erosão do solo e ajudada na melhoria da qualidade da água (TUNDISI, 2008).

As áreas do entorno das nascentes apresentam suma importância no que diz respeito à vida útil dos rios por ela abastecido, uma vez que sem a proteção adequada em torno das mesmas, nota-se um processo de degradação do rio (DONADIO; GALBIATTI; PAULA, 2005). Tais autores estudaram quatro nascentes, sendo duas com a presença de vegetação natural remanescente e duas com predominância de atividades agrícolas, e concluíram que a presença de remanescentes de vegetação de mata ciliar auxilia na proteção dos recursos hídricos. A área ocupada por essas APPs foi de $9,87 \mathrm{~km}^{2}$, o que representa $1,28 \%$ da área total do estado. 
As APPs nas encostas com declividade superior a $45^{\circ}$, ficaram dispostas, quase em sua totalidade, na face oeste do estado, na qual foram encontradas as maiores elevações do terreno e consequentemente as maiores declividades. A área ocupada pelas APPs de declividade abrange $0,24 \%$ de todo o estado, totalizando $112,48 \mathrm{~km}^{2}$.

Assis, Thomaz e Pereira (2004) relataram a ocorrência na floresta de restinga na faixa costeira do município de Guarapari, com espécies endêmicas do Espírito Santo, reforçando a importância do estado como detentor de alta diversidade e a necessidade de maior proteção desta área de preservação. Os autores relatam também que, embora a restinga seja o ecossistema mais analisado no estado do Espírito Santo em termos florísticos, há necessidade de ampliação da área geográfica nos estudos para fundamentar programas de conservação ambiental neste litoral.

Tendo em vista a importância destes ambientes para a conservação da biodiversidade, urge a necessidade de se proteger essa APP. Calculou-se a área ocupada pelas APPs em restinga e verificou-se que a mesma abrange $1,92 \%$ de todo o estado, totalizando $885,45 \mathrm{~km}^{2}$.

O manguezal é muito importante para o equilíbrio ecológico por ser uma área favorável ao desenvolvimento de diversas espécies da fauna, incluindo espécies residentes, semirresidentes e visitantes, que o utilizam como refúgio, reprodução e desenvolvimento dos filhotes até a idade juvenil, quando migram para o mar, retornando na fase adulta em épocas de reprodução, sendo esse ecossistema considerado o berçário do mar. $\mathrm{O}$ manguezal possui também uma rica flora, permanentemente verde, que fornece matéria orgânica para alimentar a extensa cadeia alimentar estuarina, costeira e marinha (ANTOLINI, 2012).

A capital do estado, Vitória, possui em seu entorno aproximadamente $11 \mathrm{~km}^{2}$ de manguezal, ecossistema estuarino, que se desenvolve no encontro das águas dos rios com o mar, nas regiões tropicais e subtropicais do planeta. Considerando a Lei 12.651, a qual descreve que toda extensão do manguezal é APP, calculou-se a área ocupada por essa APP que resultou em $88,49 \mathrm{~km}^{2}$, representando $0,19 \%$ da área total do estado.

Ao longo da costa Atlântica, face leste do estado, encontra-se uma faixa de planície que representa cerca de $40 \%$ da área total do mesmo, e, à medida que caminha para o interior, face oeste, o planalto dá origem a uma região serrana, com altitudes superiores a 1.000 metros. Sua formação geológica é modelada em rochas cristalinas e, portanto, bastante acidentada com altitudes que variam do nível do mar a 2.892 metros (Pico da Bandeira), podendo ser descrita como maré de morros. Em tais áreas encontram-se as APPs de topo de morros, sendo instrumentos de relevante interesse ambiental, elas integram o desenvolvimento sustentável dos municípios. A área ocupada por essas APPs é de 1.817,99 km², o que representa 3,95\% da área total do estado.

As áreas de preservação permanente, em altitudes superiores a 1.800 metros, encontraram-se em sua maior parte na face oeste do estado, tendo apresentado uma área de $85,48 \mathrm{~km}^{2}$ e uma representatividade de $0,19 \%$ em relação ao estado.

Os resultados mostram que a menor e a maior participação entre as categorias de APPs correspondeu às APP-3 e APP-1 com 9,90 (0,02\%) e 4.798,35 km² (10,42\%), respectivamente. Nota-se ainda que as APPs ocupam uma área total, sem sobreposições, de $7.978,44 \mathrm{~km}^{2}$, de um total de $46.052,64 \mathrm{~km}^{2}$ da área do estado, representando $17,32 \%$ de áreas que devem ser protegidas legalmente.

O percentual de APPs delimitadas neste estado (17,32\%) é inferior em relação à porcentagem encontrada em outros estudos de regiões montanhosas, como: Nascimento et al. (2005) na bacia hidrográfica do rio Alegre, Alegre - ES, que apresentou 45,95\% em relação à área de estudo; Louzada (2010) na região dos Parques Estaduais Forno Grande e Pedra Azul - ES, região serrana, com 45,9\% em relação à área de estudo; Oliveira et al. (2008) nos municípios de Alto Jequitibá, Alto Caparaó e Ervália - MG, com 48,1\% em relação à área de estudo e Eugenio et al. (2011), os quais tiveram como área de estudo o município de Alegre com extensão territorial de $773,40 \mathrm{~km}^{2}$, e que apresentou 43,50\% das áreas do município em APPs. Cabe destacar que na maior parte dos trabalhos citados foram levados em consideração apenas quatro tipos de APPs, sendo: topo de morro, nascentes, cursos d'água e declividade, sendo que o presente estudo levou em consideração as regiões serranas. 


\section{CONCLUSÕES}

Considerando as condições e metodologias adotadas no presente estudo, foi possível chegar às seguintes conclusões:

- O estado do Espírito Santo, de acordo com a Lei 12.651, possui 7.978,44 $\mathrm{km}^{2}$ de áreas de preservação permanente, representando $17,32 \%$ do estado.

- A maior concentração de APPs relacionadas às altitudes ficaram dispostas, em sua maioria na face oeste do estado.

- A APP ao longo da faixa marginal dos cursos d'água é a que possui maior representatividade, com $10,42 \%$ da área total do estado.

- Evidencia-se o fato de a discrepância entre áreas de preservação em terrenos planos, face leste do estado, em relação a terrenos montanhosos, face oeste.

\section{REFERÊNCIAS}

ANTOLINI, C. Manguezal recebe ações de proteção e recuperação. [2012]. Disponível em: <http:// www.vitoria.es.gov.br/ semmam.php?pagina=areadeprotecao>. Acesso em: 05 jul. 2013.

ASSIS, A. M.; THOMAZ, L. D.; PEREIRA. O. J. Florística de um trecho de floresta de restinga no município de Guarapari, Espírito Santo, Brasil. Acta Botânica Brasilica, Feira de Santana, v. 18, n. 1, p. 191-201, 2004.

BRASIL. LEI N. 12.651 de 25 de maio de 2012. Dispõe sobre parâmetros, definições e limites de Áreas de Preservação Permanente. Diário Oficial da União, Brasília, 25 mai. 2012. Disponível em: <http://www. planalto.gov.br/ccivil_03/_Ato2011-2014/2012/Lei/L12651.htm>. Acesso em: 01 set. 2013.

DEMERS, M. N. Fundamentals of geographic information systems. New York: John Willey \& Sons, 1997. $486 \mathrm{p}$.

DONADIO, N. M. M.; GALBIATTI, J. A.; PAULA, R. C. Qualidade da água de nascentes com diferentes usos do solo na bacia hidrográfica do córrego rico, São Paulo, Brasil. Engenharia Agrícola, Jaboticabal, v. 25, n. 1, p. 23-27, 2005.

EMBRAPA. Delimitação de topo de morro. [2013]. Disponível em: <http://www.mma.gov.br/port/ conama/processos/FBF21C00/DelimitTopoMorro_Embrapa

MonitorSatelite.pdf>. Acesso em: 10 nov. 2013.

EUGENIO, F. C. et al. Confronto do uso e cobertura da terra em áreas de preservação permanente da Bacia Hidrográfica do Rio Alegre no Município de Alegre, Espírito Santo. Engenharia Ambiental, Espírito Santo do Pinhal, v. 7, p. 110-126, 2010.

EUGENIO, F. C. et al. Identificação das áreas de preservação permanente no município de Alegre utilizando geotecnologia. Cerne, Lavras, v. 17, n. 4, p. 563-571, 2011.

EUGENIO, F. C. et al. Identificação e quantificação das áreas em conflito com a legislação ambiental brasileira para Alegre, Espírito Santo, Brasil. Revista Geográfica Venezolana, Mérida, v. 54, p. 31-45, 2013.

HOTT, M. C.; GUIMARÃES, M.; MIRANDA, E. E. Método para a determinação automática de áreas de preservação permanente em topos de morros para o Estado de São Paulo, com base em geoprocessamento. Campinas: Embrapa Monitoramento por Satélites, 2004. $32 \mathrm{p}$.

LOUZADA, F. L. R. O. Proposta de corredores ecológicos para interligação dos Parques Estaduais de Forno Grande e PEDRA Azul, ES, utilizando geotecnologia. 2010. Dissertação (Mestrado em Ciências Florestais) - Universidade Federal do Espírito Santo, Alegre, 2010.

NASCIMENTO, M. C. et al. Uso do geoprocessamento na identificação de conflito de uso da terra em áreas de preservação permanente Bacia Hidrográfica do Rio Alegre, Espírito Santo. Ciência Florestal, Santa Maria, v. 15, n. 2, p. 207-220, 2005.

OLIVEIRA, F. S. et al. Identificação de conflito de uso da terra em Áreas de preservação permanente no entorno do parque nacional do Caparaó, Estado de Minas Gerais. Revista Árvore, Viçosa, MG, n. 5, v. 32, 
p. 899-908, 2008.

TUNDISI, J. G. Water resources in the future: problems and solutions. Estudos Avançados, São Paulo, v. 22, n. 7, p. 7-16, 2008. 